\title{
A Direct Arylation-Cyclization Reaction for the Construction of Medium-Sized Rings
}

DOI:

10.1002/chem.201703527

\section{Document Version}

Accepted author manuscript

Link to publication record in Manchester Research Explorer

\section{Citation for published version (APA):}

Whitaker, D., Batuecas, M., Ricci, P., \& Larrosa, I. (2017). A Direct Arylation-Cyclization Reaction for the

Construction of Medium-Sized Rings. Chemistry: A European Journal . https://doi.org/10.1002/chem.201703527

\section{Published in:}

Chemistry: A European Journal

\section{Citing this paper}

Please note that where the full-text provided on Manchester Research Explorer is the Author Accepted Manuscript or Proof version this may differ from the final Published version. If citing, it is advised that you check and use the publisher's definitive version.

\section{General rights}

Copyright and moral rights for the publications made accessible in the Research Explorer are retained by the authors and/or other copyright owners and it is a condition of accessing publications that users recognise and abide by the legal requirements associated with these rights.

\section{Takedown policy}

If you believe that this document breaches copyright please refer to the University of Manchester's Takedown Procedures [http://man.ac.uk/04Y6Bo] or contact uml.scholarlycommunications@manchester.ac.uk providing relevant details, so we can investigate your claim.

\section{OPEN ACCESS}




\section{CHEMISTRY A European Journal}

\section{Accepted Article}

Title: A Direct Arylation-Cyclization Reaction for the Construction of Medium-Sized Rings

Authors: Daniel Whitaker, Maria Batuecas, Paolo Ricci, and Igor Larrosa

This manuscript has been accepted after peer review and appears as an Accepted Article online prior to editing, proofing, and formal publication of the final Version of Record (VoR). This work is currently citable by using the Digital Object Identifier (DOI) given below. The VoR will be published online in Early View as soon as possible and may be different to this Accepted Article as a result of editing. Readers should obtain the VoR from the journal website shown below when it is published to ensure accuracy of information. The authors are responsible for the content of this Accepted Article.

To be cited as: Chem. Eur. J. 10.1002/chem.201703527

Link to VoR: http://dx.doi.org/10.1002/chem.201703527

Supported by

ACES 


\title{
A Direct Arylation-Cyclization Reaction for the Construction of Medium-Sized Rings
}

\author{
Daniel Whitaker, María Batuecas, Paolo Ricci and Igor Larrosa*[a]
}

\begin{abstract}
A strategy for assembling biaryls linked via a mediumsized ring is herein presented. $\pi$-Complexation of fluoroarenes to chromium tricarbonyl activates the molecule towards both $\mathrm{C}-\mathrm{H}$ activation and nucleophilic aromatic substitution without covalently altering the molecular connectivity of the arene. The construction of bridged biaryl molecules with 6-10 membered core rings is achieved via a one-pot $\mathrm{C}-\mathrm{H}$ arylation/nucleophilic aromatic substitution sequence. The methodology is applicable to the synthesis of heterocyclic as well as fully carbocyclic rings.
\end{abstract}

Small rings (3-6 members) are commonly found in drug molecules. However, despite the abundance of medium ring structures in natural products, ${ }^{1}$ these rings remain rare in drug molecules, ${ }^{2}$ potentially due to the limited availability of methods for their synthesis. Indeed, it is generally acknowledged that the synthesis of medium-sized rings (7-12 members) is much more challenging than that of smaller rings. ${ }^{3}$ Methods able to form rings of varying sizes are largely restricted to lactonization, transition metal catalysed couplings, ${ }^{5}$ nucleophilic substitution, ${ }^{6}$ and metathesis reactions (Scheme 1a-c). ${ }^{7}$ A common feature of these reactions is that the ring-forming reaction is typically a synthetically distinct step requiring the molecular skeleton to be fully constructed first, often a time- and waste-intensive process. Methodologies for the formation of rings through intermolecular coupling of two separate fragments are much less common due to the requirement for compatible functional groups able to form two bonds in one synthetic step. ${ }^{8}$ Such methodologies are commonly restricted to the formation of 7 -membered rings, particularly using transition metal catalysis. ${ }^{9}$

$\mathrm{C}-\mathrm{H}$ activation has emerged in recent years as an attractive strategy for biaryl synthesis as it allows functionalization of simple and abundant $\mathrm{C}-\mathrm{H}$ bonds, and so can greatly simplify synthesis and reduce waste. ${ }^{10} \mathrm{~A}$ promising strategy, direct arylation, ${ }^{11}$ is to replace the organometallic coupling partner necessary for traditional cross coupling with an arene containing a $\mathrm{C}-\mathrm{H}$ bond able to react with a transition metal catalyst. Although many advances have been made in this field ${ }^{12}$ there remains a need to develop strategies that enable less reactive simple arenes, such as toluene, anisole or fluorobenzene, to undergo $\mathrm{C}-\mathrm{H}$ activation reactions with high reactivity and regioselectivity - current strategies either use the arene in a large excess (as solvent) and/or suffer from poor regioselectivity.

Recently, our group reported that $\pi$-complexation of simple arenes to chromium tricarbonyl dramatically increased

[a] D. Whitaker, Dr. M. Batuecas, Dr. P. Ricci, Prof. I. Larrosa School of Chemistry

University of Manchester,

Oxford Road, Manchester, UK, M13 9PL

E-mail: igor.larrosa@manchester.ac.uk

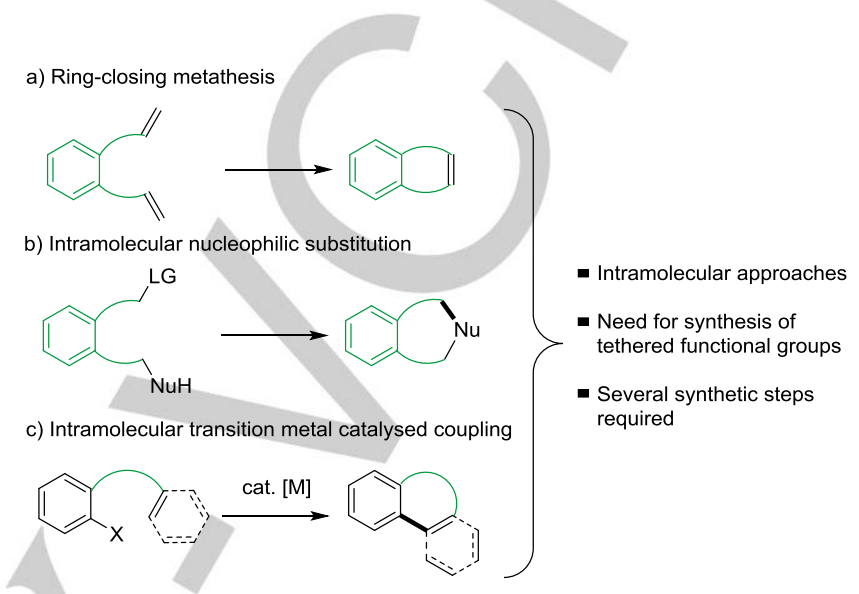

d) This work: intermolecular approach involving a one-pot direct arylation-cyclisation

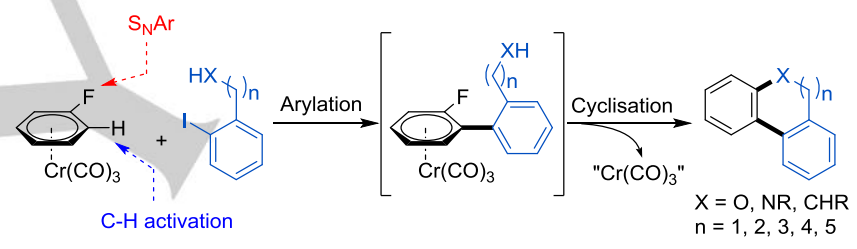

Reactivity enabled by $\mathrm{Cr}(\mathrm{CO})_{3} \pi$-complexation

One-pot intermolecular cyclisation

Scheme 1. Strategies for the formation of benzanulated medium rings

their reactivity towards biaryl formation via $\mathrm{C}-\mathrm{H}$ activation, with unprecedented regiocontrol and reactivity being observed with anisole and fluorobenzene derivatives. ${ }^{14}$ This $\pi$-complexation is also known to facilitate nucleophilic aromatic substitution $\left(\mathrm{S}_{\mathrm{N}} \mathrm{Ar}\right)^{15}$ allowing additional functionalization of the product that would not be possible without the metal.

Herein we report a strategy for the one-pot construction of bridged biaryl molecules, which exploits the dual increased reactivity of fluoroarenes towards both $\mathrm{C}-\mathrm{H}$ activation and $\mathrm{S}_{\mathrm{N}} \mathrm{Ar}$ on coordination to chromium tricarbonyl. The envisaged reaction involves direct arylation at the $\mathrm{C}-\mathrm{H}$ bond ortho to the fluorine of the $\pi$-complexed starting material, followed by nucleophilic substitution of the fluorine by a pendant nucleophile (Scheme 1d).

We began our investigation with the conditions developed for the direct arylation of 3-fluorotoluene chromium tricarbonyl complex $\mathbf{1 a},{ }^{14 a} 14$ selecting an oxygen-containing iodoarene (2a) that would form a 7-membered ring upon cyclization. No reaction was observed with the free alcohol (Table 1, entry 1), consistent with our previous observations. ${ }^{14 a}$ Instead, installing a triisopropylsilyl (TIPS) protecting group enabled the arylation step to proceed. In situ deprotection of the TIPS group with TBAF led to the cyclised product very efficiently at room temperature (Table 1, entry 2). Increasing the reaction temperature of the direct arylation step to $70^{\circ} \mathrm{C}$ improved the yield. Finally, a slight increase on the amount of silver carbonate further improved the yield, leading to the desired product in $72 \%$ yield. 
Table 1. Optimization of the one-pot direct arylation/cyclization reaction of (3 fluorotoluene $) \operatorname{Cr}(\mathrm{CO})_{3}$ (1a) with TIPS-protected 2-(2-iodophenyl) ethanol (2a)

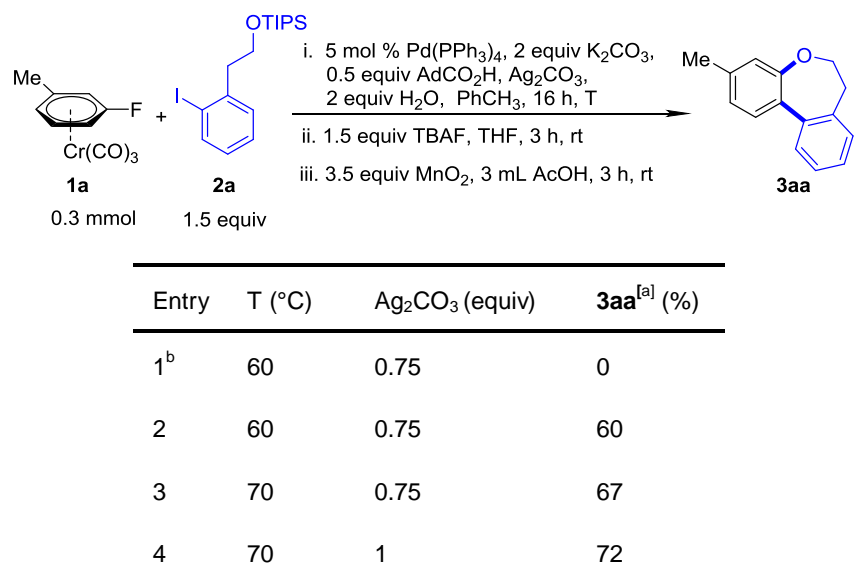

[a] Yield determined by $\mathrm{H}^{1}$ NMR by comparison with 1,3-dinitrobenzene as internal standard. [b] Unprotected alcohol used

With these conditions in hand, we explored the generality of our ring forming strategy with regards to the size of the core ring. Good yields were found for 6- and 8-membered rings (Scheme 2, 3ab and 3ae). Substrates with alkyl substituents on the core ring were also tested. Addition of a benzylic methyl group furnished the cyclised product in a good yield (3ac), although substitution by a longer, more bulky butyl chain led to a slight reduction in the yield (3ad). Previous mechanistic studies on the direct arylation reaction of arene-chromium complexes revealed that an in situ formed silver complex, $\left(\mathrm{PPh}_{3}\right) \mathrm{Ag}\left(\mathrm{O}_{2} \mathrm{CAd}\right)$, is the species responsible for the $\mathrm{C}-\mathrm{H}$ activation process. ${ }^{16}$ This investigation showed that the addition of $\mathrm{PPh}_{3}$ increased the rate of the arylation reaction due to formation of a higher concentration of $\left(\mathrm{PPh}_{3}\right) \mathrm{Ag}\left(\mathrm{O}_{2} \mathrm{CAd}\right)$. Here, we found that with less reactive iodoarenes the addition of $40 \mathrm{~mol} \%$ of $\mathrm{PPh}_{3}$ allowed good yields to be obtained.

Having demonstrated that 6-, 7- and 8-membered rings can be easily and expediently synthesised with our new intermolecular strategy, we explored the possibility of forming larger rings. In case studies of ring forming reactions, 9-10 membered rings have been found to be the most challenging to prepare due to the large enthalpic strain associated with their formation, and the lack of compensatory entropic gain seen in small rings. ${ }^{17}$ Gratifyingly, 9- and 10-membered rings (3af and 3ag) were obtained in preparatively useful yields using our onepot methodology. For these larger rings a higher yield was obtained when a strong non- nucleophilic base was added and a filtration performed between the arylation step and the alcohol deprotection, as rigorously dry conditions favoured the cyclisation over protonation of the alcohol.

We then investigated the effect of substitution on the fluoroaryl core. Hydrocarbon substituents ortho and meta to the fluorine atom were found to be reactive ( $3 \mathrm{ba}$ and $3 \mathrm{ca}$ ). Similarly, products containing free alcohols were formed from TIPSprotected benzyl alcohol substrates (3da and 3ea). An acetal group was also found to be compatible (3fa). Symmetrical arenes pose an interesting challenge for $\mathrm{C}-\mathrm{H}$ activation strategies due to the formation of mixtures of mono- and bisarylated products, ${ }^{18}$ unless there is significant electronic or steric differentiation between the starting material and product of functionalisation. Selectivity can sometimes be controlled by using a large excess of one reagent so that predominantly mono- ${ }^{13 \mathrm{f}, 19}$ or bis ${ }^{20}$ arylated products are obtained. Accordingly,
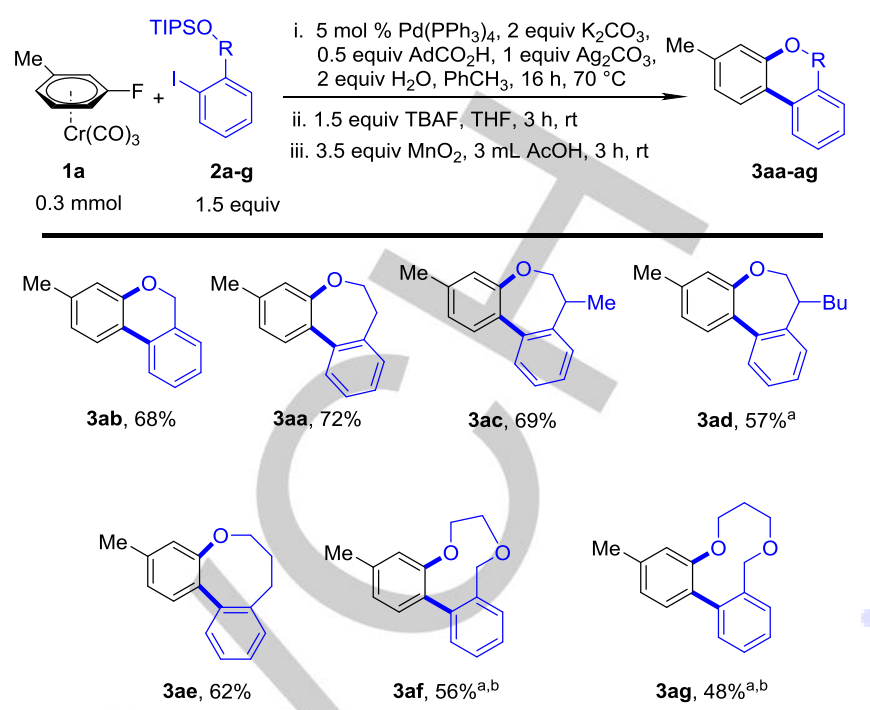

Scheme 2. Scope of the direct arylation/cyclisation reaction of (2fluorotoluene) $\mathrm{Cr}(\mathrm{CO})_{3}$ (1a) with TIPS-protected 2-lodoarenes (2a-g). [a] 40 $\mathrm{mol} \% \mathrm{PPh}_{3}$ added in step (i) [b] After step ( $i$ ) the crude reaction mixture was filtered through a short plug of silica and concentrated under reduced pressure. 4 equiv $\mathrm{NaH}$ (60\% dispersion in mineral oil) added in step (ii) Reaction time for step (ii) $16 \mathrm{~h}$.

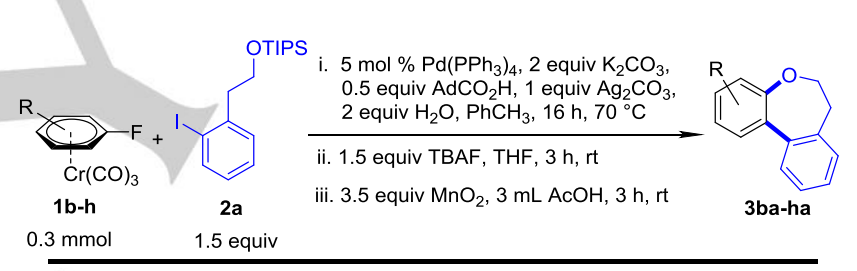

$0.3 \mathrm{mmol} \quad 1.5$ equiv

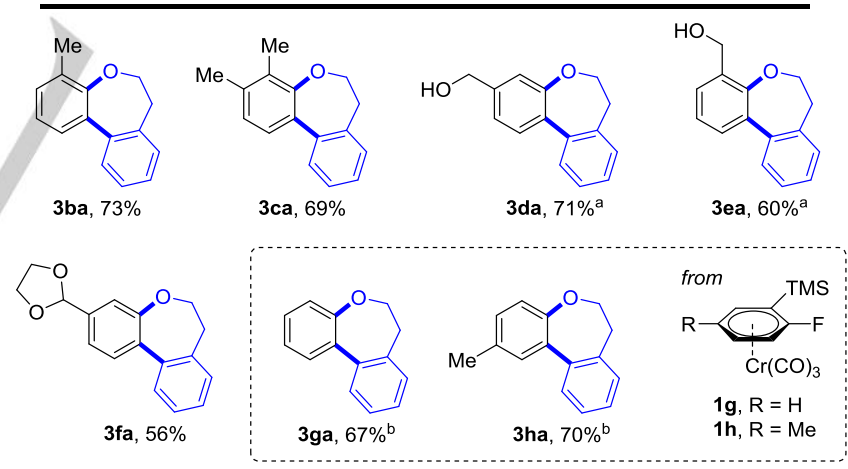

Scheme 3. Scope of the direct arylation/cyclization reaction with substituted fluoroarenes. [a] TIPS protected alcohols. 3 equiv TBAF used in step (ii). [b] From $\mathrm{Cr}(\mathrm{CO})_{3}$-complexed fluoroarenes ortho substituted with TMS. 2.5 equiv TBAF used in step (ii).

in our previous reports on arylation of fluorobenzene- $\operatorname{Cr}(\mathrm{CO})_{3}$ complexes, we had found that monoarylation of symmetrical arenes was not possible, with only bis-arylated products being accessible in good yields. ${ }^{14}$ In order to address this limitation, we developed a new strategy for accessing exclusively monoarylated products by protecting one of the two ortho positions in an otherwise symmetrical arene with a TMS group. The TMS group is easily installed via ortho-lithiation of the relevant chromium-complexed fluoroarene, and is smoothly deprotected by the fluoride salts present in the reaction conditions, enabling 
unsubstituted and para substituted arenes to be accessed (3ga and 3ha) with complete selectivity for mono- versus bis-arylation. Nitrogen-containing heterocycles are ubiquitous in both natural products and drug molecules. ${ }^{21}$ Methods for the synthesis of these molecules are therefore valuable, although nitrogen-containing molecules are notoriously challenging substrates for palladium-catalyzed $\mathrm{C}-\mathrm{H}$ arylation reactions due to the strongly coordinating ability of the nitrogen lone pair. Fortunately, Boc-protected amine $\mathbf{2 h}$ was found to be a compatible substrate for the direct arylation reaction (Scheme 4). The addition of $\mathrm{PPh}_{3}$ proved essential for achieving high reactivity in this case, potentially due to the competitive coordination of the amide to the silver carboxylate which could slow the rate of $\mathrm{C}-\mathrm{H}$ activation. In this case, efficient cyclization was effected with a strong base under dry conditions after a filtration through a plug of silica and concentration under reduced pressure.
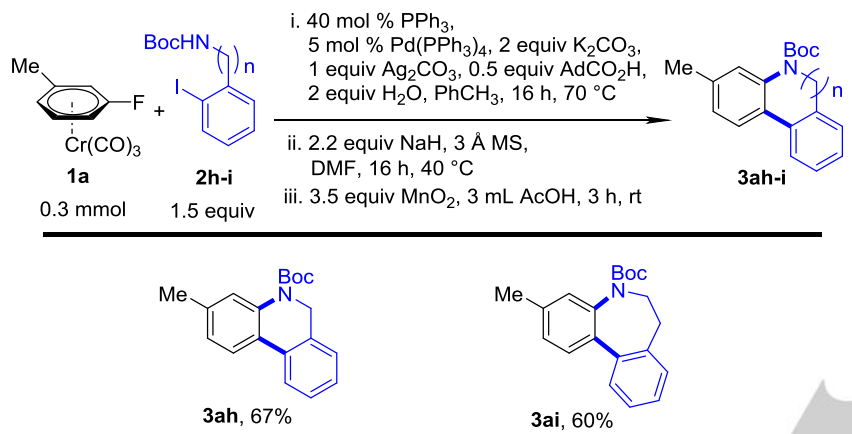

Scheme 4. Direct arylation/cyclization reaction with Boc-amide-containing iodoarenes.

Our direct arylation/cyclization strategy is not limited to Oand $\mathrm{N}$-nucleophiles and should be suitable for other nucleophiles if they are compatible with the arylation conditions. Since the ability to form two carbon-carbon bonds in one synthetic step is a valuable tool in organic synthesis, we investigated the use of an ester group as a C-nucleophile in this process. Gratifyingly, a similar strategy to that employed on Nnucleophiles allowed the synthesis of fully carbocyclic product 3ai (Scheme 5) in a preparatively useful yield.

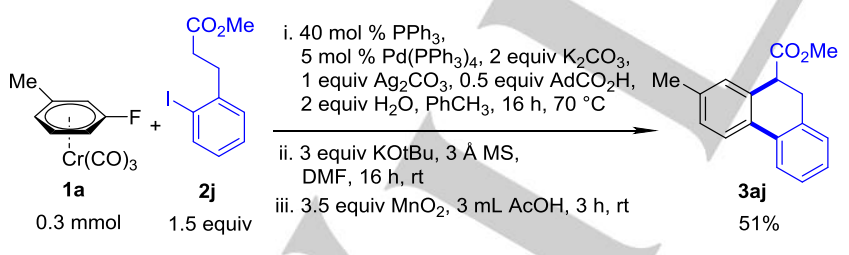

Scheme 5. Direct arylation/cyclization reaction with an ester-containing iodoarene.

In conclusion, we have developed a one-pot direct arylation-cyclization reaction that allows the facile formation of a range of medium-sized rings, including a challenging 10membered ring, exploiting the enhanced reactivity of arenechromium tricarbonyl complexes towards $\mathrm{C}-\mathrm{H}$ activation and nucleophilic aromatic substitution. The present methodology is applicable to the construction of a wide array of nitrogen- and oxygen-containing 6-10 member rings in preparatively useful yields. We have also proved that this strategy is suitable for the formation of fully carbocyclic rings in one synthetic step.

\section{Experimental Section}

General protocol for the arylation/cyclization process using TIPS-protected alcohols: $\mathrm{K}_{2} \mathrm{CO}_{3}$ (84 mg, $\left.0.6 \mathrm{mmol}\right), \mathrm{Ag}_{2} \mathrm{CO}_{3}(84$ $\mathrm{mg}, 0.3 \mathrm{mmol}), \mathrm{AdCO}_{2} \mathrm{H}(27 \mathrm{mg}, 0.15 \mathrm{mmol}), \mathrm{Pd}\left(\mathrm{PPh}_{3}\right)_{4}(18 \mathrm{mg}$, $0.015 \mathrm{mmol})$, the required $\left[\mathrm{Cr}(\right.$ fluoroarene $\left.)(\mathrm{CO})_{3}\right](0.3 \mathrm{mmol})$, and the corresponding iodoarene $(0.45 \mathrm{mmol})$ were weighed into a $10 \mathrm{~mL}$ microwave vial. The vial was sealed and purged with $\mathrm{N}_{2} . \mathrm{H}_{2} \mathrm{O}(10.8 \mu \mathrm{L}, 0.6 \mathrm{mmol})$ and toluene $(300 \mu \mathrm{L})$ were added via syringe. The reaction was heated at $70{ }^{\circ} \mathrm{C}$ for $16 \mathrm{~h}$ (stirring at $500 \mathrm{rpm}$ ), then the vial was cooled to rt. Anhydrous THF $(2.1 \mathrm{~mL})$ was added along with $0.5 \mathrm{M} \mathrm{TBAF}$ solution in THF $(0.9 \mathrm{~mL}, 0.45 \mathrm{mmol})$, and the solution vigorously stirred at $\mathrm{rt}$ for $3 \mathrm{~h}$. $\mathrm{AcOH}(3 \mathrm{~mL})$ was then added along with $\mathrm{MnO}_{2}(90 \mathrm{mg}, 1.0$ $\mathrm{mmol}$ ) and the reaction vigorously stirred at $\mathrm{rt}$ for $3 \mathrm{~h}$. The suspension was then loaded onto a short silica plug $(2 \times 2 \mathrm{~cm})$ and eluted with $\mathrm{Et}_{2} \mathrm{O}(20 \mathrm{~mL})$ before concentrating in vacuo. Column chromatography purification of the resulting crude afforded the tricyclic compounds.

\section{ACKNOWLEDGMENTS}

We gratefully acknowledge the European Research Council for a Starting Grant (to I.L.) and the Marie Curie Foundation for a Marie Skłodowska-Curie Individual Fellowship (M. B.).

[1] a) C. J. Moody, M. J. Davies, in Stud. Nat. Prod. Chem., 1992, pp. 201-239; b) P. Chattopadhyay, T. P. Majhi, B. Achari, Heterocycles 2007, 71, 1011.

[2] a) E. Vitaku, D. T. Smith, J. T. Njardarson, J. Med. Chem. 2014, 57, 10257-10274; b) A. Hussain, S. K. Yousuf, D. Mukherjee, RSC Adv. 2014, 4, 43241-43257.

[3] a) B. Greve, P. Imming, J. Org. Chem. 1997, 62, 8058-8062; b) K. C. Majumdar, RSC Adv. 2011, 1, 1152-1170.

[4] a) A. Parenty, X. Moreau, G. Niel, J.-M. Campagne, Chem. Rev. 2013, 113, 1-40; b) M. Tsakos, E. S. Schaffert, L. L. Clement, N. L. Villadsen, T. B. Poulsen, Nat. Prod. Rep. 2015, 32, 605-632.

[5] a) L. Yet, Chem. Rev. 2000, 100, 2963-3008; b) W. Zhang, J. S. Moore, Angew. Chem. Int. Ed. 2006, 45, 4416-4439; c) I. D. G. Watson, S. Ritter, F. D. Toste, J. Am. Chem. Soc. 2009, 131, 2056-2057; d) D. G. Pintori, M. F. Greaney, J. Am. Chem. Soc. 2011, 133, 1209-1211; e) N. E. Wright, S. A. Snyder, Angew. Chem. Int. Ed. 2014, 53, 3409-3413; f) B. Wang, Y. Xie, Q. Yang, G. Zhang, Z. Gu, Org. Lett. 2016, 18, 5388-5391; g)T. J. A. Corrie, L. T. Ball, C. A. Russell, G. C. Lloyd-Jones, J. Am. Chem. Soc. 2017, 139, 245-254.

[6] a) J. O. Hoberg, Tetrahedron 1998, 54, 12631-12670; b) C. J. White, A. K. Yudin, Nat. Chem. 2011, 3, 509-524.

[7] a) A. Michaut, J. Rodriguez, Angew. Chem. Int. Ed. 2006, 45, 5740-5750.; b) A. Gradillas, J. Pérez-Castells, Angew. Chem. Int. Ed. 2006, 45, 6086-6101; c) J. Cossy, S. Arseniyadis, C. Meyer, Eds., Metathesis in Natural Product Synthesis, Wiley-VCH Verlag GmbH \& Co. KGaA, Weinheim, Germany, 2010.

[8] a) F. Medina, C. Besnard, J. Lacour, Org. Lett. 2014, 16, 3232 3235; b) C.-V. T. Vo, M. U. Luescher, J. W. Bode, Nat. Chem. 2014, 6, 310-314;c) L. Ouyang, C. Qi, H. He, Y. Peng, W. Xiong, Y. Ren, H. Jiang, J. Org. Chem. 2016, 81, 912-919.

[9] a) M. Lautens, J.-F. Paquin, S. Piguel, J. Org. Chem. 2002, 67, 3972-3974; b) C. Bressy, D. Alberico, M. Lautens, J. Am. Chem. Soc. 2005, 127, 13148-13149

[10] For recent reviews on C-H activation, see: a) D. Alberico, M. E. Scott, M. Lautens, Chem. Rev. 2007, 107, 174-238.b) L. 
Ackermann, R. Vicente, A. Kapdi, Angew. Chem. Int. Ed. 2009, 48, 9792-9826; c) X. Chen, K. M. Engle, D.-H. Wang, J.-Q. Yu, Angew. Chem. Int. Ed. 2009, 48, 5094-5115; d) T. W. Lyons, M. S. Sanford, Chem. Rev. 2010, 110, 1147-1169; e) J. Wencel-Delord, T. Dröge, F. Liu, F. Glorius, Chem. Soc. Rev. 2011, 40, 4740-61; f) D. Y.-K. Chen, S. W. Youn, Chem. Eur. J. 2012, 18, 94529474.g) I. Hussain, T. Singh, Adv. Synth. Catal. 2014, 356, 16611696; h) P. H. Dixneuf, H. Doucet, Eds., C-H Bond Activation and Catalytic Functionalization I, Springer International Publishing, i) J. F. Hartwig, J. Am. Chem. Soc. 2016, 138, 2-24

[11] G. P. McGlacken, L. M. Bateman, Chem. Soc. Rev. 2009, 38, 2447-2464.

[12] For selected examples, see a) L.-C. Campeau, M. Parisien, A. Jean, K. Fagnou, J. Am. Chem. Soc. 2006, 128, 581-590; b) H. A. Chiong, Q. Pham, O. Daugulis, J. Am. Chem. Soc. 2007, 129, 9879-9884;c) R. J. Phipps, M. J. Gaunt, Science 2009, 323, 1593-1597; d) H. Li, C.-L. Sun, M. Yu, D.-G. Yu, B.-J. Li, Z.-J. Shi, Chem. Eur. J. 2011, 17, 3593-3597; e) W. Liu, H. Cao, J. Xin, L. Jin, A. Lei, Chem. Eur. J. 2011, 17, 3588-3592; f) Y. Tan, J. F. Hartwig, J. Am. Chem. Soc. 2011, 133, 3308-3311; g) Y. Aihara, N. Chatani, Chem. Sci. 2013, 4, 664-670; h) A. M. Wagner, A. J. Hickman, M. S. Sanford, J. Am. Chem. Soc. 2013, 135, 1571015713; i) D.-T. D. Tang, K. D. Collins, F. Glorius, J. Am. Chem. Soc. 2013, 135, 7450-7453; j) J. Luo, S. Preciado, I. Larrosa, J. Am. Chem. Soc. 2014, 136, 4109-4112; k) J. Tang, A. Biafora, L. J. Goossen, Angew. Chem. Int. Ed. 2015, 54, 13130-13133; I) S. Suzuki, Y. Segawa, K. Itami, J. Yamaguchi, Nat. Chem. 2015, 7, 227-233; m) J. Hubrich, T. Himmler, L. Rodefeld, L. Ackermann, ACS Catal. 2015, 5, 4089-4093; n) C. Zhu, Y. Zhang, J. Kan, H. Zhao, W. Su, Org. Lett. 2015, 17, 3418-3421; o) Q. Ding, S. Ye, G. Cheng, P. Wang, M. E. Farmer, J.-Q. Yu, J. Am. Chem. Soc. 2017, 139, 417-425.

[13] For a review, see:) N. Kuhl, M. N. Hopkinson, J. Wencel-Delord, F. Glorius, Angew. Chem. Int. Ed. 2012, 51, 10236-10254. For selected examples, see: b) D. R. Stuart, K. Fagnou, Science 2007, 316, 1172-1175; c) C. S. Yeung, X. Zhao, N. Borduas, V. M. Dong, Chem. Sci. 2010, 1, 331-336; d) X. Wang, D. Leow, J.-Q. Yu, J.
Am. Chem. Soc. 2011, 133, 13864-13867; e) T. E. Storr, M. F. Greaney, Org. Lett. 2013, 15, 1410-1413; f) S. Y. Lee, J. F. Hartwig, J. Am. Chem. Soc. 2016, 138, 15278-15284.

[14] a) P. Ricci, K. Krämer, X. C. Cambeiro, I. Larrosa, J. Am. Chem. Soc. 2013, 135, 13258-13261; b) P. Ricci, K. Krämer, I. Larrosa, J. Am. Chem. Soc. 2014, 136, 18082-18086.

[15] For reviews see: a) F. Rose-Munch, E. Rose, in Modern Arene Chemistry, Wiley-VCH Verlag $\mathrm{GmbH}$ \& Co. KGaA, Weinheim, FRG, 2002, pp. 368-399; b) M. F. Semmelhack, A. Chlenov, in Transition Metal Arene $\pi$-Complexes in Organic Synthesis and Cataysis., Springer Berlin Heidelberg, 2004, pp. 43-69. For selected examples, see: c) Y. Yamamoto, H. Danjo, K. Yamaguchi, T. Imamoto, J. Organomet. Chem. 2008, 693, 3546-3552; d) S. Shirakawa, K. Yamamoto, K. Maruoka, Angew. Chem. Int. Ed. 2015, 54, 838-840; e) S. Kinoshita, K. Kamikawa, Tetrahedron 2016, 72, 5202-5207.

[16] D. Whitaker, J. Burés, I. Larrosa, J. Am. Chem. Soc. 2016, 138, 8384-8387.

[17] C. Galli, L. Mandolini, Eur. J. Org. Chem. 2000, 2000, 3117-3125.

[21] a) M. Lafrance, C. N. Rowley, T. K. Woo, K. Fagnou, J. Am. Chem. Soc. 2006, 128, 8754-6; b) T. A. Boebel, J. F. Hartwig, J. Am. Chem. Soc. 2008, 130, 7534-7535; c) L. Ackermann, E. Diers, A. Manvar, Org. Lett. 2012, 14, 1154-1157; d) D. Leow, G. Li, T.-S. Mei, J.-Q. Yu, Nature 2012, 486, 518-22; e) X. S. Zhang, Q. L. Zhu, Y. F. Zhang, Y. B. Li, Z. J. Shi, Chem. Eur. J. 2013, 19, 11898-11903.

[19] Y.-N. Wang, X.-Q. Guo, X.-H. Zhu, R. Zhong, L.-H. Cai, X.-F. Hou, Chem. Commun. 2012, 48, 10437

[20] a) L. Ackermann, A. Althammer, R. Born, Angew. Chem. Int. Ed. 2006, 45, 2619-2622; b) T. Mei, R. Giri, N. Maugel, J. Yu, Angew. Chem. Int. Ed. 2008, 47, 5215-5219; c) S. Zhang, G. He, Y. Zhao, K. Wright, W. A. Nack, G. Chen, J. Am. Chem. Soc. 2012, 134, 7313-7316; d) M. Simonetti, D. M. Cannas, A. Panigrahi, S. Kujawa, M. Kryjewski, P. Xie, I. Larrosa, Chem. Eur. J. 2016, 1-6.

[21] E. Vitaku, D. T. Smith, J. T. Njardarson, J. Med. Chem. 2014, 57 , 10257-10274 


\section{Entry for the Table of Contents}

\section{COMMUNICATION}

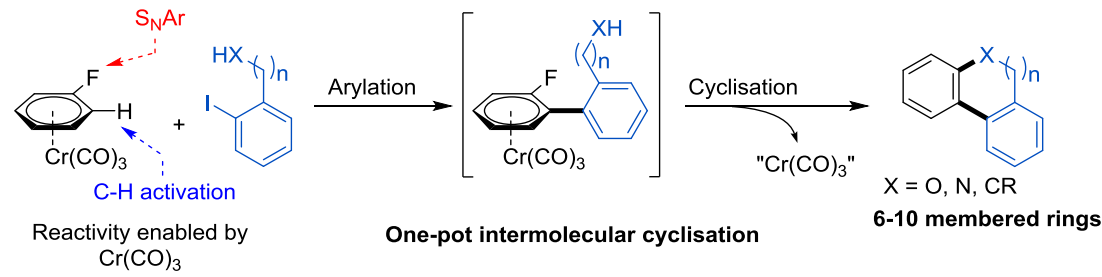

An intermolecular cyclisation reaction has been developed, combining direct $\mathrm{C}-\mathrm{H}$ arylation with nucleophilic aromatic substitution. $\pi$-complexation of fluoroarenes to $\mathrm{Cr}(\mathrm{CO})_{3}$ greatly enhances the reactivity of both steps. Rings with 6 to 10 members are accessible through cyclisation with $\mathrm{O}, \mathrm{N}$ and $\mathrm{C}$-centered nucleophiles.
Daniel Whitaker, María Batuecas, Paolo Ricci and Igor Larrosa*

Page No. - Page No.

A Direct Arylation-Cyclization Reaction for the Construction of Medium-Sized Rings 